

\section{O movimento KONY 2012 no YouTube: ativismo civil e a vida moral on-line ${ }^{1}$}

\author{
The KONY 2012 movement \\ on YouTube: civil activism and \\ the moral life on-line
}

\author{
Guilherme Mendes Pereira2
}

\section{Resumo}

Procuramos neste estudo investigar os aspectos morais relacionados à veiculação e propagação na Internet da campanha humanitária KONY 2012. Percebemos que apesar da aparente inquestionabilidade desta, a responsabilidade moral no contexto cibermediado mostra-se bastante complexa e problemática. Conforme ponderamos a partir das teses de Giddens (1991), Vattimo (1994) e Bauman (1997), principalmente, a moralidade atualmente encontra-se esfacelada. Tudo gera dissenso; e mesmo as grandes causas estão sujeitas a questionamento. Esta pesquisa é uma tentativa de ilustrar e comentar essas teses, situando-as no contexto da mídia digital interativa e global. Assim, argumentamos que as ditas tecnologias emancipatórias não são favoráveis quando há carência de consciência e responsabilidade moral.

\section{Palavras-chave}

Comunicação Social; cibercultura; moralidade; ativismo civil; KONY 2012.

\section{Abstract}

In this study we seek to investigate the moral aspects related to the placement and spread of the Internet humanitarian campaign KONY 2012. We realized that despite this apparent unquestionability, moral responsibility in cibermediated context appears to be quite complex and problematic. As we reflected from Giddens (1991), Vattimo (1994) and Bauman (1997) theses mainly, currently morality is crumbling. Everything generates dissent; and even great causes are subject to questioning. This research is an effort to illustrate and comment on these theses, placing them in the context of global digital and interactive media. Thus, we argue that the so-called emancipatory technologies are not favorable when there is lack of awareness and moral responsibility.

\section{Keywords}

Media; cyberculture; morality; civil activism; KONY 2012.

|MAGINAR' 


\section{Introdução}

Este texto articula algumas das reflexões desenvolvidas na dissertação apresentada ao Programa de Pós-Graduação em Comunicação Social da PUCRS no primeiro semestre de 2014.

Nosso objetivo nesse estudo foi compreender os aspectos morais contidos na veiculação pela Internet da campanha humanitária e política chamada KONY 2012, concebida pela fundação filantrópica Invisible Children (IC). A sua repercussão tornou esse movimento um fenômeno relevante da cibercultura. Assim, por meio deste, pôde-se analisar alguns dos problemas, paradoxos e desafios da comunicação e ativismo social em nosso tempo.

A ação denunciava Joseph Kony, atuante em Uganda desde o final da década de 1980 e que tem comandado o Lord's Resistance Army (LRA), organização que é responsável pelo cometimento de crimes hediondos contra milhares de famílias e, notadamente, crianças de seu país. Para combater as ações do LRA, a campanha KONY 2012, em síntese, propôs que civis, em todo o mundo, peticionassem às autoridades e aos governos internacionais, por meio de ações on-line e de protestos nas ruas, o apoio militar internacional ao governo de Uganda para que este conseguisse extinguir as ações de Kony e de seu exército.

O movimento começou com a publicação no site YouTube e a difusão, via redes sociais da internet, de um vídeo em formato de documentário, em março de 2012, intitulado KONY 2012. Esse audiovisual alcançou, no período de uma semana, um recorde de visualizações: mais de 100 milhões em apenas seis dias. Isso o tornou um dos "virais" mais bem-sucedidos da história recente da Internet, motivando numerosas discussões na esfera pública e, também, ampla cobertura nos circuitos midiáticos tradicionais.
Estudamos o fenômeno supracitado com base em dois eixos, cada um com posicionamentos morais diversos: movimento e contramovimento. O movimento KONY 2012 refere-se a produções que foram importantes para a popularização da causa, como o documentário que motivou a ação, o ativismo nas ruas e a produção e divulgação na Internet de manifestações culturais favoráveis à ação. Já o contramovimento KONY 2012 consistiu em atos que questionaram a causa ou tentaram pôr em xeque as suas mensagens, objetivos e ações, como produções ciberativistas amadoras e discussões por meio de comentários de texto no site YouTube.

Com base no exame do fenômeno KONY 2012, incidente numa época em que diferentes possibilidades de exercício da cidadania e de governança são colocadas à baila por meio do ciberativismo e outras formas de participação on-line, destacamos uma questão que foi importante ao desenvolvimento deste estudo: considerando que o ativismo cibermediado prima pela distribuição do poder político via redes e que, para tanto, proporciona uma espécie de Ágora, na qual todos podem participar e lançar suas opiniões parece-nos que essa "redemocratização" da esfera pública tem ganhado força junto ao fenômeno de cacofonia comunicacional. Este, por sua vez, tem tornado o espaço e a vida moral ainda mais complexos.

O movimento e o contramovimento gerados por KONY 2012 acabaram por revelar de forma pertinente a relação das socialidades com a responsabilidade moral na contemporaneidade. No cibermundo, todos parecem reivindicar o direito de se exibir, de participar e de opinar. Em meio a esse burburinho e excitação potencializados pelos cibermeios, parece que a questão da responsabilidade moral tem perdido sentido e propósito.

Desenvolvemos o presente estudo com base em confrontações históricas e sociológicas, procurando en- tender as ambivalências e paradoxos das socialidades contemporâneas. Nossa matriz metodológica segue algumas premissas indicadas por Rüdiger (2011, p. 288):

[...] a reflexão crítica sobre os fenômenos, as tendências e o sentido da cibercultura exige que pensemos como articulação cotidiana de um pensamento tecnológico e um capitalismo maquinístico, sem perder de vista os limites e oportunidades presentes na dialética entre utopia emancipatória e extensão tecnológica de nossos projetos de poderio ilimitado, entre fantasia regressiva e criação revolucionária, entre mito e razão, contida em seu processo de formação histórica.

Para dar conta disso, comentamos sobre o fenômeno do campo da comunicação aqui explicitado com base nas discussões a respeito da moralidade e ética no mundo contemporâneo, tendo como principais referências Giddens (1991), Vattimo (1994) e Bauman (1997).

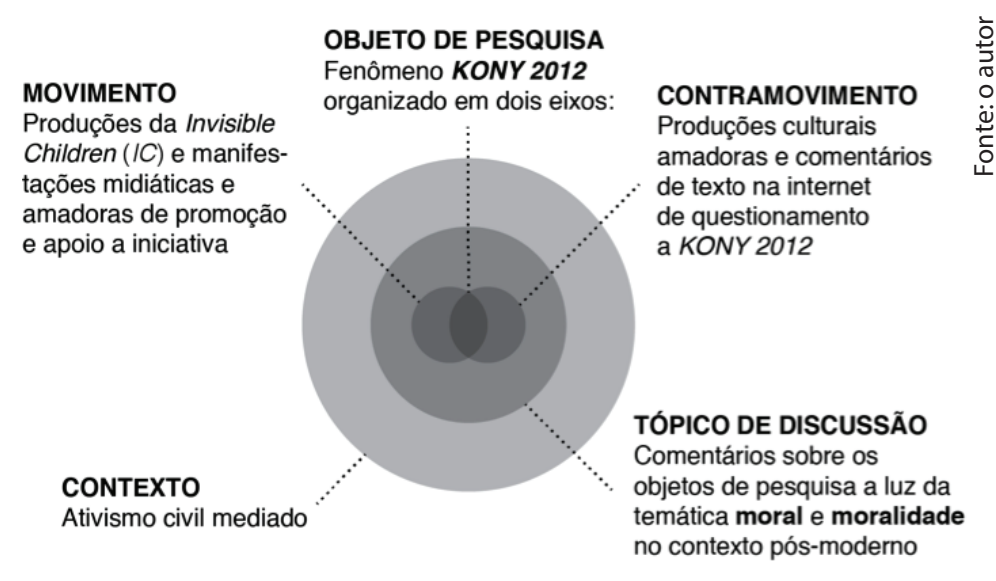

Figura 1: gráfico ilustrando os eixos de estudo 
Na Figura 1 esquematizamos, em linhas gerais, os direcionamentos para o desenvolvimento da pesquisa.

\section{A ação KONY 2012 e as}

movimentações sociais

Entendemos que o ciberativismo acontece por meio de grupos que se compõem e se organizam no cibermundo por meio de tensionamentos sociais de cooperação e disputa que acabam por reforçar causas ou por deslegitimá-las. Cabe destacar que, no presente estudo, concentramo-nos na observação das rela-

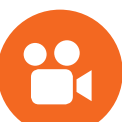

\section{ASSISTA AO VÍDEO}

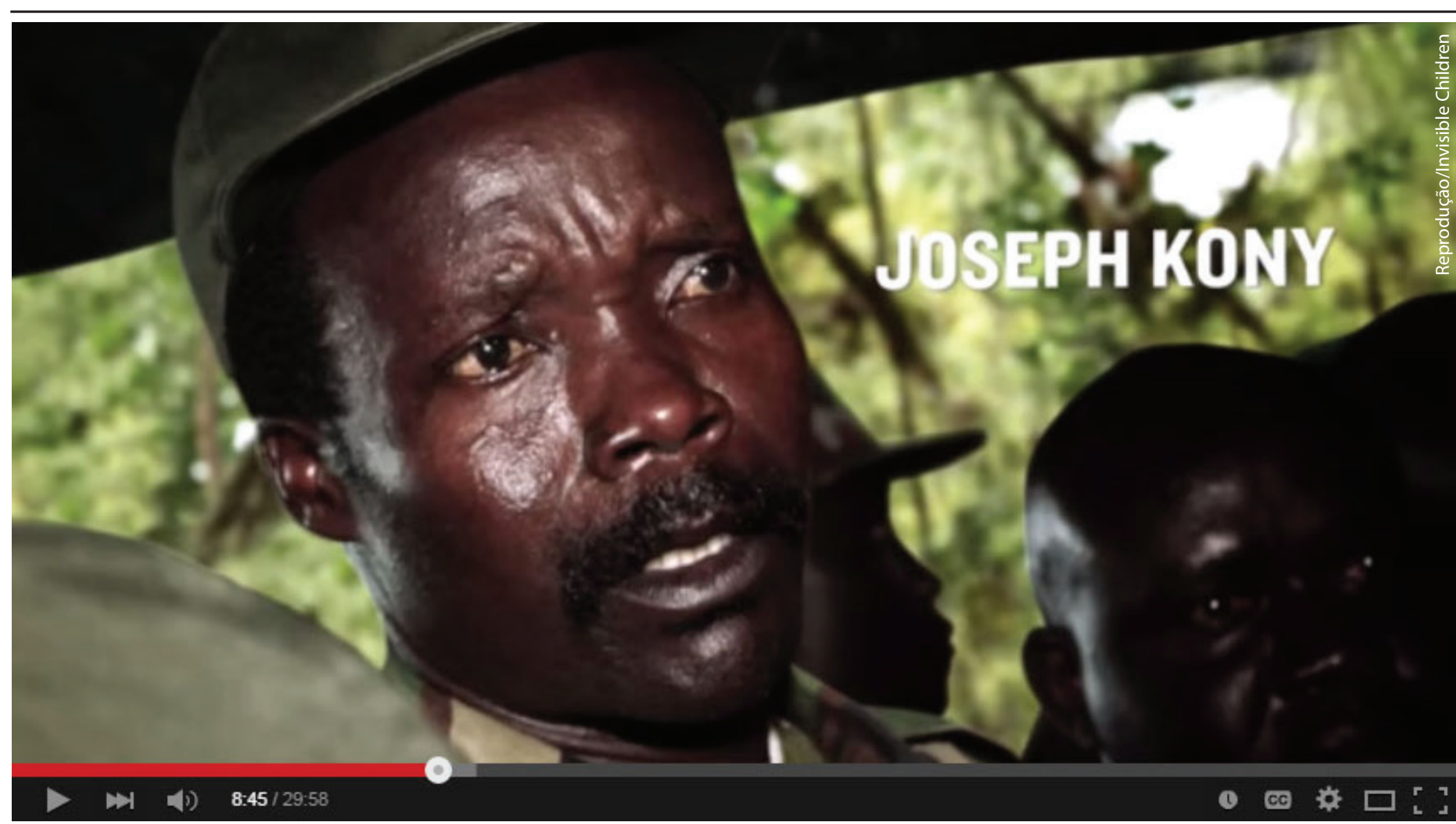

ções sociais e comunicacionais com base em alguns desdobramentos registrados nas redes on-line. Ou seja, nosso foco de análise abrangeu a recepção e a participação de atores sociais, restringindo-os a determinado enfoque temático: o fenômeno de cacofonia e de complexificação da vida moral no cibermundo.

Nosso mote para tal empreendimento foi: o vídeo original KONY 2012; menções em alguns veículos midiáticos tradicionais à causa; algumas produções audiovisuais amadoras postadas no site YouTube; e comentários de texto correlacionados a estas ${ }^{3}$. Todos esses elementos fo- ram importantes no processo de popularização/discussão e legitimação/ deslegitimação da iniciativa KONY 2012.

A partir da documentação e análise do referido corpus, verificamos que Joseph Kony não tinha sido capturado. Todavia seguiram a repercutir boatos (principalmente em comentários de textos adjacentes a vídeos no YouTube) como, por exemplo, de que ele estaria morto ou de que viveria noutro país. Também foram observadas polêmicas nas conversações em rede envolvendo a IC, como a de uma possível relação corrupta entre essa instituição e o governo estadunidense em função da existência de fontes petrolíferas em Uganda. Situamos nesse eixo discursos de alguns grupos ativistas on-line minoritários. Trata-se de amadores que manifestaram suas ideias e relatos por meio de filmes e comentários textuais em resposta a KONY 2012, fenômeno que entendemos aqui como contramovimento.

Os partidários do movimento KONY2012, por sua vez, também produziram diversas mensagens sobre a causa, as quais repetiam o discurso humanitário promovido pela IC. Muitos destes demostraram desconhecimento acerca de inúmeros aspectos políticos e históricos de Uganda, conforme diversos comentários documentados no texto completo desta pesquisa. Nesse grupo estão os ciberativistas que se dispuseram a ações com base em ímpetos coletivos e apelos estéticos.

Além disso, em outros eixos opinativos foi observada uma miscelânea de discursos que relativizaram e divergiram de outras premissas morais documentadas, lançando sátiras, paródias ou narrativas nonsense.

Nesse contexto, verificamos que o mote KONY 2012 tem sustentando um amplo processo de conversação cibermediada, o qual serviu como estopim para uma pluralidade de discussões. Estas tangenciaram desde

47 PORTO ALEGRE | v. 19 | n. 32 | 2014 | pp. $45-51$ Sessões do Imaginário 
assuntos sobre política e história internacional até argumentações individuais que relativizaram noções de cidadania, moralidade e ética.

\section{A questão da moralidade no mundo on-line}

Bauman (1997), que discorreu sobre a complexidade da vida moral na pós-modernidade, sustenta que

[...] vivemos e agimos na companhia de uma multidão aparentemente infinda de outros seres humanos, vistos ou supostos, conhecidos ou desconhecidos, cuja vida e ações dependem do que fazemos e que influenciam por sua vez o que fazemos o que podemos fazer e o que devemos fazer - e tudo isso de maneiras que nem entendemos nem somos capazes de prever. Nessa vida, precisamos de conhecimento e capacidades morais com mais frequência, e com mais urgência, que de qualquer conhecimento das "leis da natureza" ou de capacidades técnicas. Todavia, não sabemos onde consegui-los; e quando (se) se nos oferecem raramente estamos seguros de que neles podemos confiar com firmeza (sic) (Bauman, 1997, p.23-24).

Nesse sentido, pontuamos o modelo de ética pós-moderna de Bauman como uma referência que pode contribuir na reflexão sobre a necessidade de tornarmo-nos mais cientes da amplitude das consequências de nossas ações num mundo socialmente constituído por meio da informação e pela comunicação mediada. E isso pode orientar-nos na otimista tarefa de nos tornarmos indivíduos moralmente mais responsáveis. Conforme esse autor, começamos a intuir essa conduta ética pós-moderna na medida em que compreendemos e aceitamos o caos, a ambivalência e a incerteza como elementos fundadores e constituintes de nossas socialidades fragmentárias e de nossos ímpetos à racionalização do mundo.

KONY 2012 e seus desdobramentos comunicacionais sugerem-nos que, mais que nunca, está próxima de nós a consciência da nossa condição de incerteza, ambivalência e caos. Essas características acabam por constituir nossos espaços sociais; e, paradoxalmente, também se tornam espécies de linhas de força que conformam nossas socialidades e ímpetos morais.

Observando esse pensamento, parece que o caos, apesar da carga semântica negativa desde a sua etimologia, que remonta às mitologias pré-filosóficas, não consiste no abismo obscuro do cenário atual; muito pelo contrário, o caos pode ser a oportunidade para, em meio ao contexto de liberdade extrema que nos apresenta intuirmos um senso de responsabilidade moral talvez mais apurado. Por exemplo, no caso de KONY 2012, ao nos depararmos com a produção original e os vídeos e comentários de texto que o contestam, podemos observar uma divergente amplitude de manifestações morais. Não há uma indicação única e certeira de qual posicionamento é "mais" ou "menos" moral, "mais" ou "menos" humano. Cada um tem a liberdade de observar a pluralidade com que se defronta interpretar e fazer a sua escolha. Nesse sentido, podemos talvez desenvolver, por meio deste exercício de escolha, uma espécie de autonomia moral como contraponto à heteronomia do estado e de instituições ou dos impulsos estéticos coletivos que assolam o espaço moral na pós-modernidade, segundo indicam-nos Vattimo (1992) e Bauman (1997).

Nesse contexto emergente, singular e ao mesmo tempo plural, Vattimo (1992) defende que, em vez de alcançarmos o ideal de uma sociedade mais transparente e esclarecida, parece que atingimos um estágio em que predomina a complexidade, a cacofonia e o caos. E nesse contexto é que encontrar-se-iam as nossas perspectivas atuais de emancipação.

Para o autor, que revisita a ideia de grandes narrativas de Jean François Lyotard, a dissolução dos pontos de vista totalizantes foi possível graças à emergência dos meios de comunicação de massa, que permitiram a eclosão e multiplicação de visões de mundo. Esse autor ilustra tal constatação por meio do fenômeno de popularização de grupos minoritários e de subculturas nos circuitos midiáticos mainstream. A aparente democratização do direito à palavra - que não necessariamente incidiu em maior emancipação política - foi ao encontro da lógica do mercado da informação, que passou a postular que tudo se tornaria objeto de comunicação. Conforme Vattimo (1992, p. 13),

[...] a intensificação das possibilidades de informação sobre a realidade nos seus mais variados aspectos torna cada vez menos concebível a própria ideia de realidade. [...] Realidade, para nós, é mais o resultado do cruzamento, da contaminação (no sentido latino) das múltiplas imagens, interpretações, reconstruções que, em concorrência entre si ou, seja como for, sem qualquer coordenação central, os media distribuem.

Ele afirma que, nesse paradigma da comunicação generalizada, o ideal de emancipação parte agora da multiplicidade, da oscilação, da caoticidade e do próprio desgaste da ideia de realidade. Isso está na contramão do ideal de emancipação moderno, que se baseava no cânon de alcance do conhecimento perfeito das coisas por meio da razão, o que conformaria sujeitos comple- 
tamente cientes de si e das estruturas da realidade.

Nesse sentido, Vattimo (1992) também fala da importância do pensamento de Martin Heidegger, quem, junto a Nietzsche, foi seminal para refletir sobre esse contexto de viragem hermenêutica e de abalo das estruturas paradigmáticas modernas. Para Vattimo (1992), esses filósofos revelaram que pensar a realidade com base no ser, ordenada a partir da razão, da metafísica e da Ciência, mostrou-se como mais uma mitologia. Tal arcabouço seria mais um meio para poder dominar e organizar todas as coisas e seres, reduzindo-os a imagens e presenças quantificáveis.

Com a proliferação de imagens na pós-modernidade, o sentido unitário de realidade acabou entrando em colapso. E esse choque, explica Vattimo (1992), terminou por indicar outras possibilidades de emancipação. O desenraizamento seria uma dessas possibilidades, o qual propõe a libertação das diferenças e das peculiaridades locais por meio das potencialidades da comunicação generalizada. Isso traz à tona uma pluralidade de vozes, que, agora, podem ser ouvidas globalmente. Esse autor sustenta que

O efeito emancipador da libertação das racionalidades locais não é, todavia apenas o de garantir a cada uma delas um mais completo reconhecimento e autenticidade; como se a emancipação consistisse em manifestar finalmente aquilo que cada um é verdadeiramente (ainda em termos metafísicos, espinosianos): negro, mulher, homossexual, protestante, etc. O sentido emancipador da libertação das diferenças e dos dialetos consiste mais no efeito global de desenraizamento que acompanha o primeiro efeito de identificação. Se falo o meu dialeto, finalmente, num mundo de dialetos entre outros, se professo o meu sistema de valores [...] neste mundo de culturas plurais, terei também uma consciência intensa da historicidade, contingência, limitação, de todos estes sistemas, a começar pelo meu (Vattimo, 1992, p.15).

Apesar de problemática, pois não se baseia na certeza e estabilidade da razão, essa liberdade de experiência, que nos abre ao diálogo, à fruição espontânea dos acontecimentos e à interpretação constante pode nos tornar capazes de alcançar outros modos de ser, quem sabe mais humanos, conforme infere, em tom otimista, o autor.

A possibilidade de livre encontro com outros mundos e com outros modos de ser pode nos mostrar a possibilidade de usufruir do livre-arbítrio enquanto experiência oscilatória entre pertença e desenraizamento na dita sociedade da comunicação generalizada. Agora, podemos navegar por entre essas ambivalências, escolher e assumir nossas escolhas e a responsabilidade por estas.

\section{Considerações finais}

O movimento e o contramovimento KONY 2012 mostraram-nos que, apesar da aparente inquestionabilidade da causa em questão, a responsabilidade moral continua sendo complexa e problemática. Esta é continuamente delegada ao próximo, quando não rejeitada.

Muitos dos atores sociais que tiveram suas produções ou manifestações a respeito de KONY 2012 documentadas na versão completa deste estudo, parecem se encaixar no perfil do turista. Vagueando despropositadamente, depararam-se com mais um assunto da moda que, de forma muito rápida, caiu no gosto popular, e, da mesma forma foi velozmente esquecido.
É fato que muitos desses ativistas transcenderam o cibermundo e foram às ruas em algum momento. Mas, uma vez alcançados seus objetivos individuais, voltaram aos seus recônditos cotidianos, com a consciência aliviada, e acabaram, assim, por abandonar as movimentações.

A situação calamitosa de atentados a civis pelo grupo terrorista LRA em Uganda continua. Isso é inclusive mostrado no site da IC 4 . Mas, apesar disso, as mobilizações não reincidiram com a mesma potência, como no início da campanha KONY 2012.

Por outro lado, havia também os desfavoráveis à causa, que a criticaram e apontaram problemas pelas comunicações nas redes. Nesse caso, também podemos questionar sobre a responsabilidade moral desses indivíduos. Fiéis aos seus discursos, eles acreditavam estar agindo em prol de um "bem maior", ao esclarecerem aos outros sobre possíveis "inverdades". No entanto, nesse caso, também assumiram uma parcela de responsabilidade moral e, depois, desapareceram no vazio do cibermundo.

A condição do moralista e de seus adversários, conforme Bauman (1997) parece se confundir com a do turista no mundo moderno: passamos por iniciativas e ações, não nos comprometemos com estas, mas nos sentimos no direito de opinar, sem nos aprofundarmos muito. Nesse sentido, questionamos se o descompromisso e a superficialidade confundidos com a moralidade não estariam se tornando lugares-comuns.

Na sociedade tecnológica na qual parecem prevalecer os ímpetos estéticos (as comoções coletivas das multidões), os meios precedem aos fins, alerta o pensador supracitado. $E$, ao passo que a vida torna-se cada vez mais mediada, acabamos presos num descompasso existencial intermitente. A lógica do progresso é amparada pela perspectiva de que importa sempre ir adian- 
te, superar, mesmo não se tendo plena ciência do "porquê" e do "para quê". É a eterna busca pelo poder em si. Conforme Friedrich Nietzsche, a "vontade de vontade".

Todavia, como bem sabemos, a técnica não é moralmente neutra; necessita, assim, de avaliação moral e de controle ético. Isso tem amplificado a comunicação, mas promovido nosso distanciamento face a face, o que é desfavorável ao espaço moral, conforme Bauman (1997).

Segundo a ideia de reflexividade ou circularidade do conhecimento social indicada por Giddens (1991), a regulação ética da modernidade tem sido pautada por protocolos técnicos e tecnológicos que visam amparar a solução de problemas morais que venham a acontecer. Essa mediação tecnológica da existência incide na anulação de distâncias, na transformação de contextos e na suspensão das responsabilidades. São as descontinuidades da modernidade sinalizadas por esse estudioso, ambivalente característica da modernidade radicalizada.

A cada inovadora solução tecnológica que chega com a resolução miraculosa de problemas anteriores, são criados novos problemas, os quais têm sua resolução postergada. Através do imperar tecnológico, fragmenta-se a totalidade e a complexidade das relações e das realidades em múltiplas e independentes partes. Partes essas que devem ser tratadas separadamente aos possíveis efeitos colaterais de suas proposições, que acabam por fugir do escopo de responsabilidades da moral individual. A vida é, desse modo, cindida numa sucessão de problemas a serem continuamente postergados.

Para Bauman (1997), isso tem se refletido no apagamento da responsabilidade moral em detrimento da liberdade sem excedentes e do ímpeto continuo à transgressão. Mais vale aproveitar as possibilidades da vida suspensa pelo consumo, pelos ímpetos coletivos e pelas mágicas cibermedialidades do que preocupar-se em demasia ou dedicar-se a algo já que não chegaremos a lugar algum mesmo.

Essa dispersão da existência acaba por obliterar nosso moribundo eu moral, que demanda noção do todo e lucidez. Trata-se de um mundo que parece ser uma justaposição de imagens e contextos soltos e parciais, justificando aí a sua impossibilidade de compreensão (e não apreensão) total, implicando na escusa de responsabilidade moral. Só se pode ser responsável pelo que (ou por quem) se pode apreender, manejar, mensurar e ter. O sujeito, assim, em sua fragmentária incompletude, vagueia entre problemas momentâneos conforme suas conveniências.

Movimentos sociais, luta pelas minorias, ciberativismo, protestos nas ruas, cultura da participação e redemocratização social por meio da Internet são assuntos da vez. Esse ideário e motivações cambiantes têm pautado discussões e movimentações constantes e plenas de entusiasmo. Movimentações que surgem e desaparecem como espectros na velocidade insana da dinâmica do cibermundo.

Giddens (1991) defende a necessidade do realismo utópico, materializado por meio do ativismo. Mas é preciso ir além dos superficiais e caóticos burburinhos dos protestos cibermediados que afloram a todo o momento.

Os movimentos sociais, comenta Bauman (1997), incidem em anseios individuais, causas fragmentadas que ganham potência quando expressas no vácuo estético das neotribos. Movimentos sociais reforçam a imagem de mundo que só pode ser assimilado por meio de sua divisão em quantas partes for possível. Cada parte, assim, é passível de ser tratada e resolvida de forma independente das demais. Isso tem contribuído, segundo o autor, para a "[...] substituição de normas éticas por padrões de eficiência, e responsabilidade moral por procedimento técnico" (Bauman, 1997, p. 227).
O método de "dividir para conquistar", atribuído ao imperador romano César e reiterado no racionalismo de Descartes, que apoiou o desenvolvimento da Ciência moderna, tem revelado-se pouco apropriado que tange à administração da vida social pós-moderna.

As discussões produzidas por meio do movimento KONY 2012 e das reações contrárias geradas por este (contramovimento) servem para nos mostrar que de nada servem tecnologias emancipatórias, ações com propostas miraculosas ou a inferência de opiniões arbitrárias na esfera pública, na grande Ágora digital, quando faltam consciência e responsabilidade moral.

Doar dinheiro a uma organização ou replicar informações, ou até mesmo contra-atacar quem faz isso, não sanará com problemas complexos. Mas se, ao invés disso, tomarmos consciência da historicidade de problemas e pautarmos ações cotidianas disciplinadas em relação ao outro e aos nossos espaços em suas totalidades, talvez, aí sim, consigamos resoluções quem sabe mais eficazes para os nossos problemas e dilemas morais. Isso seria a concretização do realismo utópico de Giddens (1991), orientado pela ética pós-moderna postulada por Bauman (1997).

Essa ética pós-moderna propõe que o indivíduo aceite suas "fundações movediças", amparadas na ambivalência e incerteza; e enseje ser um modelo na tarefa de tentar prever problemáticas e de compreender e lidar com os percalços presentes, sempre tendo consciência e ponderando com base no entendimento mais amplo da vida social. Para esse autor, junto desse modelo de ética caminha a autonomia da responsabilidade moral:

A responsabilidade moral é a mais pessoal e inalienável das posses humanas, e o mais precioso dos direitos humanos. Não pode ser eliminada, 
partilhada, cedida, penhorada ou depositada em custódia segura. A responsabilidade moral é incondicional e infinita, e manifesta-se na constante tortura de não se manifestar a si mesma suficientemente. A responsabilidade moral não busca resseguro para o seu direito de ser ou para escusas do seu direito de não ser. Está aí antes de qualquer resseguro ou prova e depois de qualquer escusa ou absolvição (Bauman, 1997, p.285).

Tal idealismo filosófico ainda é um sonho, uma utopia, confessa Bauman (1997). Mas quem dera um dia se tornasse uma realidade. Por isso, é importante tomar partido e defender essa responsabilidade. Quem sabe, pelo exercício paulatino da reflexão e pelo exemplo pontual, essa responsabilidade, em dado momento, ganhe força como um viral e contagie multidões.

Percebemos então, com base nas teses de Giddens (1991), Vattimo (1994) e Bauman (1997) que a moralidade encontra-se atualmente esfacelada. Tudo gera dissenso; mesmo as grandes causas estão sujeitas a questionamento. Esta pesquisa foi uma tentativa de ilustrar e comentar essas teses, situando-as no contexto da mídia digital, interativa e global, por meio de um estudo de caso.

Nossas expectativas de um futuro melhor talvez possam encontrar novo alento na lucidez advinda do aumento da consciência moral. Essa consciência alerta-nos que o que tem importância no que tange as nossas reponsabilidades morais é o que de fato fazemos ou deixamos de fazer.

O poeta Eduardo Galeano, certa vez, refletiu em Voces de Nuestro Tiempo: "Somos o que fazemos principalmente o que fazemos para mudar o que somos". Por meio da consciência por uma ética pós-moderna, podemos perceber que temas morais não podem ser resolvidos.

Se cada ação nossa repercute, de alguma forma, na vida de outras pessoas, e isso foi potencializado por meio das tecnologias cibernéticas, o sentido ético de nossas escolhas e atuações segue sendo algo fundamental na vida contemporânea. A questão que fica é: como a conduta moral manter-se-á como um aspecto relevante e consistente da ação social e política do caótico e irrefreável cibermundo da comunicação do século XXI?

\section{Referências}

BAUMAN, Zygmunt. Ética pós-moderna. São Paulo: Paulus, 1997.

GIDDENS, Anthony. As consequências da modernidade. São Paulo: UNESP, 1991.

PEREIRA, Guilherme Mendes. KONY 2012: ativismo civil e a vida moral no cibermundo. 2014. 132f. Dissertação (Mestrado em Comunicação Social) - Faculdade de Comunicação Social, PUCRS, Porto Alegre, 2014.

RÜDIGER, Francisco. As teorias de cibercultura: perspectivas, questões e autores. Porto Alegre: Sulina, 2011.

VATTIMO, Gianne. A sociedade transparente. Lisboa: Relógio D'água, 1992.

\section{Notas}

1 Trabalho desenvolvido com o apoio da CAPES por meio de bolsa de estudos modalidade parcial.
2 Doutorando do Programa de Pós-Graduação em Comunicação Social da Pontifícia Universidade Católica do Rio Grande do Sul (PUCRS). Especialista em Linguagens Verbais e Visuais e suas Tecnologias pelo Instituto Federal Sul-Rio-grandense (IFSUL). (PPGCOM/PUCRS - Av. Ipiranga, 6681, Prédio 7, CEP: 90619-900, Porto Alegre/RS, Brasil). E-mail: guilhermefranconi@gmail.com.

3 O detalhamento completo do corpus referido pode ser acessado na íntegra na pesquisa completa "KONY 2012: ativismo civil e a vida moral no cibermundo" (PEREIRA, 2014).

4 Disponível em: <http://invisiblechildren.com/>. Acesso em: 13 dez. 2013 